\title{
Erratum to: Exogenous Application of Selenium Mitigates Cadmium Toxicity in Brassica juncea L. (Czern \& Cross) by Up-Regulating Antioxidative System and Secondary Metabolites
}

\author{
Parvaiz Ahmad $^{1,3}$ - E. F. Abd Allah ${ }^{2}$ Abeer Hashem ${ }^{3,4} \cdot$ Maryam Sarwat $^{5}$ • \\ Salih Gucel $^{6}$
}

Published online: 25 October 2016

(C) Springer Science+Business Media New York 2016

\section{Erratum to: J Plant Growth Regul \\ DOI 10.1007/s00344-016-9592-3}

The affiliation of Parvaiz Ahmad has an update. The correct information is published with this erratum.

The online version of the original article can be found under doi:10.1007/s00344-016-9592-3.

Parvaiz Ahmad

parvaizbot@yahoo.com

1 Department of Botany, S.P. College, Srinagar,

Jammu and Kashmir 190001, India

2 Department of Plant Production, Faculty of Food \& Agricultural Sciences, King Saud University, Riyadh, Saudi Arabia

3 Department of Botany and Microbiology, Faculty of Science, King Saud University, Riyadh 11451, Saudi Arabia

4 Mycology and Plant Disease Survey Department, Plant Pathology Research Institute, Agriculture Research Center, Giza, Egypt

5 Pharmaceutical Biotechnology, Amity Institute of Pharmacy, Amity University, Noida, Uttar Pradesh 201303, India

6 Centre for Environmental Research, Near East University, Lefkosa (Nicosia), Cyprus 